\title{
The Role of Osteoprotegerin as a Cardioprotective Versus Reactive Inflammatory Marker: the Chicken or the Egg Paradox
}

\author{
Flora Özkalayc11, Öykü Gülmez¹, Betül Uğur-Altun², Seithikurippu Ratnas Pandi-Perumal², \\ Armağan Altun 1
}

\author{
${ }^{1}$ Department of Cardiology, Başkent University İstanbul Hospital, İstanbul, Turkey \\ ${ }^{2}$ Department of Endocrinology and Metabolism, Başkent University İstanbul Hospital, İstanbul, Turkey \\ ${ }^{3}$ Somnogen Canada Inc., College Street, Toronto, Canada
}

Cardiovascular disease is one of the most frequent causes of mortality and morbidity worldwide. Several variables have been identified as risk factors for cardiovascular disease. Recently, the role of receptor activator of nuclear factor kappa B, receptor activator of nuclear factor kappa B ligand, and the osteoprotegerin system has been recognized as more important in the pathogenesis of cardiovascular disease. Besides their roles in the regulation of bone resorption, these molecules have been reported to be associated with the pathophysiology of cardiovascular disease. There are conflicting data regarding the impact of osteoprotegerin, a glycoprotein with a regulatory role in the cardiovascular system. The aim of this review is to discuss the current knowledge and the role of osteoprotegerin in cardiovascular disease.

Keywords: Cardiovascular disease, heart, inflammatory markers, osteoprotegerin
Cardiovascular disease (CVD) is one of the most frequent causes of mortality and morbidity among both men and women worldwide (1). Several studies conducted on CVD pathogenesis have identified several variables as risk factors (2-5). The complex pathophysiology of CVD is still a point of interest. In recent years, the role of receptor activator of nuclear factor kappa B (RANK), RANK ligand (RANK-L), and the osteoprotegerin (OPG) system has been receiving more research attention in terms of the pathogenesis of CVD. OPG was first described by Simonet et al. (6) as a regulator protein for bone metabolism and vascular calcification, which is produced by several tissues, including smooth muscle cells and the endothelium of the human vasculature (7-10). In addition to their roles in the regulation of bone resorption in calcium and immunologic reactions, RANK, RANK-L, and the OPG system have also been found to be associated with CVD pathophysiology (7-9). Several trials have reported higher OPG plasma levels in patients with coronary artery disease (CAD), peripheral artery disease (PAD), chronic heart failure (CHF), and atrial fibrillation, suggesting the association between OPG and CVD (11-16).

\section{OSTEOPROTEGERIN: STRUCTURE, FUNCTION, AND METABOLISM}

OPG is a soluble glycoprotein that is synthesized from 401 amino acid residues arranged into 7 structural domains (Figure 1). After losing 21 amino acids, it converts into a mature soluble glycoprotein with 380 amino acids. It is found in the extracellular fluid in the form of either a $60-\mathrm{kDa}$ monomer or a $120-\mathrm{kDa}$ dimer, linked by disulfide bonds. OPG is a member of the tumor necrosis factor (TNF) receptor superfamily and serves as a decoy receptor for RANK-L and TNFrelated apoptosis-inducing ligand (TRAIL). OPG is also a key protein for bone metabolism. By binding to RANK-L, OPG inhibits the interaction between RANK and RANK-L, which prevents the osteoclastic differentiation of stromal cells. On the other hand, by binding to TRAIL, it inhibits the apoptosis of transformed cells and tumor cells (6-9).

Of the 7 structural domains of OPG, domains 1-4 contain cysteinerich N-terminal amino acids. These domains bind to RANK-L and inhibit osteoclast formation from osteoclast precursors. Domains 5-6 bind to TRAIL and inhibit TRAIL-induced apoptosis. Domain 7 contains the $\mathrm{C}$-terminal amino acid, which is the heparin-binding region of OPG $(10,17,18)$. Although OPG is primarily produced by bone marrow stromal cells, it can also be expressed in dendritic cells and B lymphocytes (19). 1- $\alpha 25$ hydroxycholecalciferol, interleukin-1 (IL-1), TNF- $\alpha$, IL-6, IL-7, IL-11, IL-18, calcium and estrogen, transforming growth factor beta, bone morphogenetic protein-2, fibroblast growth factor, angiotensin 2, and plateletderived growth factor are known to upregulate the expression of OPG, whereas immunosuppressants, parathyroid hormone,

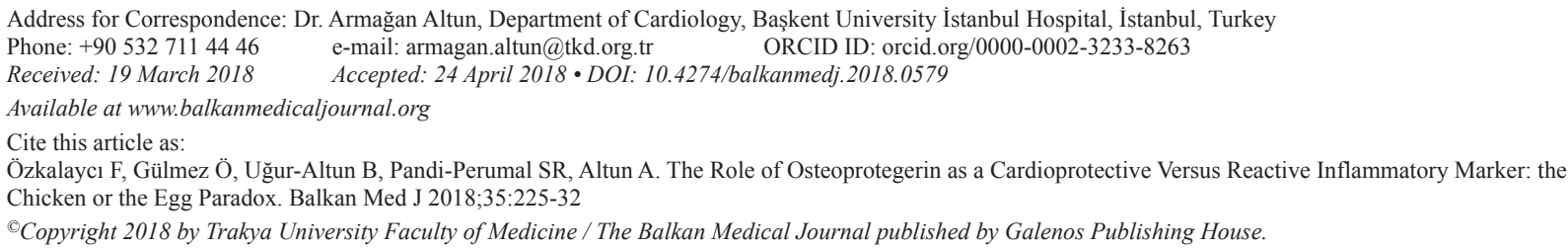


glucocorticoids, insulin-like growth factor-1, prostaglandin E2, and peroxisome proliferator-activated receptor gamma ligands downregulate OPG production (20-23). The tensile force applied on osteoblasts is a mechanical stimulus that also increases OPG synthesis. Moreover, several studies have demonstrated that aerobic exercise is associated with increased OPG levels (24).

Serum OPG levels are associated with its renal clearance. OPG levels increase with the reduction of renal creatinine clearance (25). Further increases can be seen in patients with end-stage renal disease receiving hemodialysis, as OPG monomer cannot be removed through the polysulfone membrane during hemodialysis (25). In addition, OPG level increases with advanced age, especially in the presence of diabetes mellitus (DM) (14,26-31). Most of the epidemiologic studies have demonstrated a positive correlation between age and OPG levels (30,31). OPG levels were found to be increased with age in both men and women (30). Premenopausal women had higher OPG levels than men below age 50 years, whereas postmenopausal women had similar OPG serum levels compared with an age-matched male population (30). Moreover, in the Dallas Heart Study, women had higher OPG levels than men, which were compatible with the majority of other epidemiologic studies $(32,33)$. Based on these results, investigators also concluded that gender difference in OPG levels suggests that sex steroids regulate OPG expression in vivo (34). Estrogen enhancement of OPG secretion by osteoblastic cells may play a major role in the antiresorptive action of estrogen on bone (35). Khosla et al. (30) demonstrated that OPG levels were positively correlated with bone turnover markers in the male gender. In another study, parenteral administration of OPG prevented bone resorption in postmenopausal women (36). These studies suggest that OPG levels increase concomitantly with bone turnover markers as a compensatory response to enhanced bone resorption process. Moreover, there are several studies indicating that OPG deficiency is primarily associated with osteoporosis and arterial calcification $(13,37)$. In addition, osteoporosis was reported to be accompanied by severe vascular calcification in OPG-deficient mice (7).

\section{Relationship Between Osteoprotegerin Levels and Cardiovascular Disease}

Coronary artery calcification (CAC) is a well-known indicator for atherosclerotic plaque burden. The factors that interfere with $\mathrm{CAC}$ also interfere with coronary atherosclerosis and CVD, respectively (38). According to clinical studies, vascular calcium burden is an indicative marker for the severity of atherosclerosis

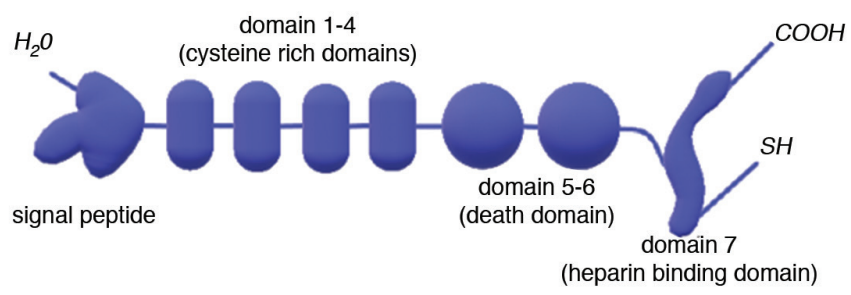

FIG. 1. Schematic drawing of the osteoprotogerin molecule. and arteriolosclerosis (39). Several studies have shown that the RANK-RANK-L-OPG system is related to atherosclerotic plaque calcification $(40,41)$.

Relationship between osteoprotegerin levels and stable coronary artery disease: Several studies have shown that OPG levels are predictive of CAD $(11,12,42,43)$. Lieb et al. (11) measured OPG levels in 3.250 Framingham Heart Study participants and found a positive association between circulating OPG levels (but not RANK-L) and CVD incidence and mortality. Some investigators have demonstrated a positive correlation between circulating OPG levels and the severity of atherosclerosis and the number of diseased vessels, especially in patients with type 2 DM $(12,26,42)$. Ghaffari et al. (43) reported a significant relationship between serum OPG levels and coronary artery stenosis. Furthermore, they found that major adverse cardiovascular events occurred more often in patients with higher baseline OPG levels. Kiechl et al. (44) concluded that OPG was an independent risk factor for the onset of CVD and progression of atherosclerosis. In addition, they found that OPG was independently and significantly related to incident CVD and vascular mortality (44). Poornima et al. (45) showed that in postmenopausal women, the higher OPG levels were associated with higher CAC. In a study comparing OPG levels between patients with cardiac syndrome X (CSX), healthy obese subjects, and healthy lean subjects, it was found that OPG levels were significantly lower in patients with CSX than those in healthy lean subjects. The authors concluded that low OPG levels might play a role in systemic microvascular abnormalities observed in patients with CSX (46). OPG levels were found to be indicative of cardiovascular morbidity and mortality in patients with chronic kidney disease (47-49).

TABLE 1. Comparison of serum osteoprotegerin levels in different patient populations

\begin{tabular}{|c|c|}
\hline & OPG \\
\hline Healthy subjects & $\leftrightarrow$ \\
\hline Stable CAD & $\uparrow$ \\
\hline $\mathrm{ACS}$ & $\uparrow \uparrow$ \\
\hline STEMI & $\uparrow \uparrow$ \\
\hline NSTEMI & $\uparrow \uparrow$ \\
\hline PAD & $\leftrightarrow \uparrow$ \\
\hline Stroke & $\leftrightarrow \uparrow$ \\
\hline $\mathrm{CHF}$ & $\uparrow$ \\
\hline Valvular heart disease & $\downarrow$ \\
\hline Hypertension & $\leftrightarrow \uparrow$ \\
\hline DM & $\leftrightarrow \uparrow$ \\
\hline DM with end-organ damage & $\uparrow$ \\
\hline Obesity & $\leftrightarrow \uparrow \downarrow$ \\
\hline Metabolic syndrome & $\leftrightarrow \uparrow \downarrow$ \\
\hline Hyperlipidemia & $\leftrightarrow \uparrow$ \\
\hline \multicolumn{2}{|c|}{$\begin{array}{l}\text { ACS: acute coronary syndrome; CAD: coronary artery disease; CHF: chronic heart } \\
\text { failure; DM: diabetes mellitus; NSTEMI: myocardial infarction without ST elevation; } \\
\text { OPG: osteoprotegerin; PAD: peripheral artery disease; STEMI: myocardial infarction } \\
\text { with ST elevation; } \leftrightarrow \text { : normal level; } \uparrow: \text { increased level; } \uparrow \uparrow: \text { more increased level; } \\
\leftrightarrow \uparrow: \text { normal level or increased level; } \downarrow \text { : decreased level; } \uparrow \downarrow: \text { conflict results }\end{array}$} \\
\hline
\end{tabular}


Relationship between osteoprotegerin levels and Acute Coronary syndrome: In patients with ST-elevation myocardial infarction (STEMI) who underwent primary percutaneous coronary intervention, the OPG levels were found to be significantly associated with worse long-term cardiac outcomes (50). Jansson et al. (51) showed that OPG was an independent predictor for longterm mortality and CHF in patients with unstable angina pectoris (USAP). Moreover, Luo et al. (52) investigated OPG and OPG/ RANK-L levels in patients with stable angina pectoris (SAP) and Acute Coronary syndrome (ACS). They found that serum OPG and OPG/RANK-L levels were significantly higher in the ACS group than in the SAP group. In the control group, which consisted of healhy subjects, the OPG and OPG/RANK-L levels were significantly lower than those of both the ACS and the SAP groups (52). However, in another study involving patients with SAP, USAP, and non-STEMI, the OPG levels showed no correlation with the severity of CAD, which might be due to OPG and/or RANK-L polymorphism and some other possible genetic variations, but it may be accepted as an indicator of coronary atherosclerosis (53). Higher OPG levels detected in patients with ACS might be associated with increased cytokine levels. This increase may be a proatherogenic pathway for further inflammation. Zauli et al. (54) showed that endogenously released OPG in response to TNF- $\alpha$ promoted an increased expression of adhesion molecules and leukocyteendothelial cell interaction, which aggravates inflammation.

\section{Relationship Between Osteoprotegerin Levels and Peripheral Artery Disease}

Multiple studies that had been carried out in various patient groups to evaluate the association between OPG and PAD found significant correlations (55-57). OPG levels appear to predict PAD in several patient groups. Lee et al. (56) demonstrated a positive correlation between OPG levels and cardio-ankle vascular index, which predicts atherosclerosis in hypertensive patients, thus suggesting arterial stiffness. In a study performed in patients with type 2 DM, serum OPG levels were higher in those with PAD than in those without PAD (57). In another study involving patients with nonalcoholic fatty liver disease (NAFLD), the OPG level was found to be higher in patients who had lower aortic flow propagation velocity and higher epicardial fat thickness (58).

\section{Relationship Between Osteoprotegerin Levels and Stroke}

Several studies have demonstrated higher OPG levels in patients with atherosclerotic cerebrovascular disease than those in healthy subjects $(44,59,60)$. Carotid intima-media thickness (CIMT) is one of the risk factors predicting stroke and CVD $(61,62)$. Kiechl et al. (44) also showed that OPG levels were associated with the severity and progression of carotid artery disease. Patients with chronic kidney disease and patients with increased OPG levels had significantly higher CIMT values than those in subjects with lower OPG levels (47). In women with gestational DM, increased serum OPG levels showed a positive correlation with CIMT (59). There are conflicting data regarding the association between stroke severity and OPG levels. In one study, no association was found between the risk of ischemic stroke and OPG levels (63). However, another study reported that plasma OPG levels were higher in patients with severe stroke (64). Mogelvang et al. (60) evaluated the association between plasma OPG and high sensitive C-reactive protein (CRP) levels and hospitalization for ischemic stroke, ischemic heart disease (IHD), and all-cause mortality. They found that OPG levels were an independent predictor of combined endpoints of ischemic stroke, IHD, and all-cause mortality. Along with the predictive value of OPG in ischemic stroke, Guldiken et al. (65) demonstrated that OPG was also associated with stroke subtypes.

\section{Relationship Between Osteoprotegerin Levels and Chronic Heart Failure}

OPG is a secretory glycoprotein that may exert a compensatory response to increased inflammatory activity in patients with CHF. Omland et al. (66) assessed the relationship between OPG levels and left ventricular (LV) function in patients who were enrolled in the Dallas Heart study. High levels of OPG were found to be associated with increased LV end-systolic volume and decreased LV ejection fraction (66). After adjusting for potential confounders in sex-specific multivariable models, OPG levels were found to be positively correlated with LV thickness, mass, and LV concentricity index in men, but not in women (66). In another study, serum OPG levels were predictive of CHF development in patients with ACS, independent of conventional risk markers such as troponin I, CRP, B-type natriuretic peptide, and ejection fraction (67). Moreover, $\mathrm{CHF}$ was shown to be associated with increased OPG-RANK-RANK-L axis, indicating inflammation characterized by matrix degradation and remodeling of the myocardial tissue (16).

\section{Relationship Between Osteoprotegerin Levels and Valvular Heart Disease}

Valvular heart disease is associated with inflammation and calcification of valve tissue. Proinflammatory cytokines activate the endothelial cells and increase OPG release (68). It was shown that increased OPG levels were associated with decreased osteoclastic differentiation in stenosis of aortic valves (69). Moreover, calcification of aortic valves in the elderly has been attributed to the inflammatory milieu, which promotes the osteogenic transformation of valvular cells $(69,70)$. $\mathrm{LDLr}^{-/}$mice expressing only apolipoprotein B100 were prone to develop aortic valve calcification. Weiss et al. (71) investigated the impact of exogenous OPG on aortic valve calcification in hypercholesterolemic LDLr -F Apob100/100 mice and found that exogen OPG attenuates osteogenic transformation of valve cells and bone-like matrix synthesis, indicating that the aortic valve function was protected by the OPG treatment (71).

\section{Relationship Between Osteoprotegerin Levels and Hypertension}

The renin-angiotensin-aldosterone system is one of the hallmarks in blood pressure regulation. Some studies have demonstrated the indirect effects of angiotensin II on the activation of osteoclasts via the activation of RANK-L gene expression in osteoblasts $(72,73)$. Based on these data, it can be speculated that blood pressure and OPG may have an interactive relationship. It has been shown that angiotensin II 
blockage downregulates OPG levels in vitro, suggesting the possible link between high OPG levels and increased blood pressure (74). It may be suggested that increased OPG levels might be a protective response to vascular stiffness observed in hypertensive subjects. Wang et al. (75) showed that patients with higher carotid-femoral pulse wave velocity measurement, which is a gold standard for assessing arterial stiffness (76), had higher OPG levels. In the Dallas Heart study, higher OPG levels were also associated with hypertension (32). Browner et al. (14) showed that OPG levels were slightly higher in women with high blood pressure than in those with normal blood pressure, especially in patients aged $\geq 65$ years (14). These results may be attributed to the relationship between OPG levels, arterial stiffness, and inflammation. Hypertension and arterial stiffness associated with vascular calcification and decreased elasticity may increase inflammation and expression on OPG in order to decrease the vascular stiffness (33). In several studies, the association between OPG levels and blood pressure was assessed along with other cardiovascular risk factors. Akyuz et al. (77) compared the OPG levels of resistant and nonresistant hypertension in patients with Obstructive Sleep Apnea syndrome. They also assessed the relationship between CIMT, apneahypopnea index (AHI), and OPG levels among the study groups. They found that OPG levels were higher in patients with resistant hypertension than in patients with nonresistant hypertension (77). Moreover, they found no relationship between AHI and OPG levels but showed a positive correlation between CIMT and OPG levels in resistant hypertensive patients. However, this finding did not suggest a direct cause-and-effect relationship between higher OPG levels and high blood pressure (77). In contrast to these findings, no significant relationships were found between blood pressure and OPG levels in a Korean women study that was performed in premenopausal and postmenopausal women (78). The difference in the results between these two studies might be due to the different characteristics of the study participants and the different assays used to measure OPG levels $(77,78)$.

\section{Relationship Between Osteoprotegerin Levels and Diabetes Mellitus}

Numerous studies have shown that serum OPG levels were higher in patients with DM than in those without DM $(28,14,79)$. Different investigators have reported that serum OPG levels were increased in patients with type 1 and type 2 DM $(28,80,81)$. OPG levels were also found to be higher in patients with longer duration of DM. Furthermore, in patients with DM and CVD, serum OPG levels were found to be higher than those in patients with DM and without CVD $(81,82)$. OPG levels were shown to predict subclinical atherosclerosis and near-term cardiovascular events in uncomplicated type 2 DM (42). Diabetic end-organ damage was more likely to be observed in patients with higher OPG levels (28). In a study designed to determine whether OPG could be a marker for nephropathy in type 1 DM, OPG levels were found to be high only in patients with nephropathy; however, there was no significant relationship between other microvascular and macrovascular complications and OPG levels (83). Experimental studies have shown that increased OPG levels in patients with DM were related to proinflammatory cytokines such as TNF- $\alpha$ and IL-6 rather than high serum glucose levels (84). These data indicate that the increased OPG levels in patients with DM are related to proinflammatory cytokines but are not related to insulin and high glucose levels $(79,84,85)$.

\section{Relationship Between Osteoprotegerin Levels and Obesity}

There is still a conflict of data regarding the relationship between obesity and serum OPG levels, which might be attributed to the difference between the sample groups and methods, such as comorbidities and demographic features of patients of each study and the assays used for measuring OPG levels. Gannage-Yared et al. (86) found no correlation between body mass index and OPG levels, but they showed a positive correlation between insulin sensitivity and CRP levels and OPG levels in obese patients, suggesting that the inflammatory process in obesity promotes OPG increase. Ashley et al. (24) designed a study to examine the relationship between OPG levels, obesity, and insulin sensitivity in a healthy population. OPG levels were found to be significantly lower in obese subjects than in normal-weight and overweight subjects. In addition, a positive relationship was found between OPG levels and insulin sensitivity among all subjects (24). Consistent with these findings, a study involving obese, healthy, and lean subjects found that OPG levels were significantly lower in the obese group than in the lean controls (87). Furthermore, lower OPG levels were found in obese subjects with elevated insulin resistance than those found in lean subjects and in obese subjects with low insulin resistance (87). The relation between circulating OPG and insulin resistance assessed HOMA-IR was in investigated at obese and normal-weight women in premenopausal period (88). OPG showed a negative correlation with insulin and HOMA-IR in premenopausal obese women (88). According to these results, it may be suggested that increased insulin levels are associated with decreased OPG levels. The mechanism of decreased OPG levels in insulin-resistant obese subjects remains unclear. Several studies have shown that lower OPG levels observed in obese subjects are attributed to the possible inhibitory effect of insulin on OPG expression $(89,90)$. In an experimental study designed with 9 healthy male subjects, it was shown that acute hyperglycemia did not increase OPG levels in nondiabetic subjects, whereas hyperinsulinemia inhibited OPG expression (89). This finding might be attributed to a possible inhibitory effect of insulin on OPG expression and explain the decreased OPG levels in healthy obese subjects.

\section{Relationship Between Osteoprotegerin Levels and Metabolic Syndrome}

Considering that the Metabolic syndrome (MetS) is a state of obesity, insulin resistance, and inflammation, increased white adipose tissue (WAT) in obese subjects has become a much important issue $(91,92)$. WAT acts as an endocrine organ that promotes inflammation due to its macrophage-rich content $(93,94)$. As inflammation promotes OPG expression, it can be suggested that OPG levels are accepted to be higher in patients with MetS. On the other hand, there are conflicting data regarding the relationship between OPG levels and MetS. According to animal studies, OPG levels were found to be increased in mice fed with a high-fat diet (95). Bernardi et al. (95) reported higher OPG levels in newly 
diagnosed MetS group than in healthy subjects after adjusting for other risk factors, which might be due to the inflammatory milieu in MetS causing increased OPG expression. However, some investigators suggest that there is no correlation between MetS and serum OPG levels (86). The different results may be attributed to the different study groups differing in terms of variables such as sex, age, comorbidities, and diagnostic criteria of MetS.

\section{Relationship Between Osteoprotegerin Levels and Hyperlipidemia}

The relationship between lipid profile and OPG levels is still a matter of debate. Lipid profile has been the subject of few studies, and controversial reports have been published (15, 26,96). The different results obtained are attributed to different study populations. In Korean healthy female subjects, higher total cholesterol and low-density lipoprotein (LDL) levels were associated with higher OPG levels (78). In the Dallas Heart study (32), the participants' higher OPG levels were found to be associated with hypercholesterolemia. In contrast, GannageYared et al. (86) found no correlation between OPG levels and lipid profile in obese subjects. These studies suggest that the increased OPG expression is a protective response to elevated LDL levels that promote the atherosclerotic process. Moreover, it can be speculated that higher OPG levels in hypercholesterolemia are a result of the inflammatory milieu caused by increased LDL and total cholesterol levels. LDL-lowering therapy was shown to have conflicting results in patients with type $2 \mathrm{DM}$. Although simvastatin treatment reduced OPG levels (96), lovastatin and pravastatin treatment increased the plasma levels of OPG $(97,98)$.

\section{ROLE OF OSTEOPROTEGERIN AS A CARDIOPROTECTIVE VERSUS REACTIVE INFLAMMATORY MARKER: THE CHICKEN OR THE EGG PARADOX}

Recent studies have demonstrated that serum OPG levels are a strong predictor of cardiovascular mortality and morbidity $(11,12)$. In a systematic review performed by Hosbond et al. (99), the authors evaluated the relationship between OPG and CAD, ACS, PAD, and cerebrovascular disease. They analyzed 14 studies with clearly defined cohorts and found that OPG levels are associated with the presence and severity of stable CAD, ACS, and cerebrovascular disease, but not associated with PAD. The atherosclerotic process involves mechanical and immunological mechanisms, and arterial calcification is an important indicator of atherosclerotic plaque burden. According to recent studies, in contrast to our previous knowledge, vascular calcification is an actively regulated process and human vascular smooth muscle cells can express osteoblastic transcription factors $(100,101)$ and bone-regulating proteins such as matrix Gla protein, osteopontin, osteocalcin, collagen 1, osteonectin, bone morphogenic proteins, alkaline phosphatase, and bone sialoprotein. The calcification can occur either in an intimal or in a medial layer of arteries. Remodeling of the arterial wall includes degeneration of elastin fibers, increase in collagen fibers, and thickening of the arterial wall $(102,103)$. As a result, calcification of elastic components of the medial layer increases the arterial wall thickness, thus causing arterial stiffness. Increased arterial stiffness causes arterial shear stress on the vascular wall and hence develops a tendency to atherosclerosis (104). Based on these data, it can be speculated that OPG is a protective mediator for atherosclerosis due to the inhibition of vascular calcification.

Atherosclerosis is also an immunological process. In an experimental study performed on unstable coronary plaques, increased expression levels of RANK-L from $\mathrm{T}$ cells and RANK from monocyte series were demonstrated by Shaker et al. (105). Therefore, it has been suggested that the increase in RANK-L is related to the increase in leukocyte response and matrix degradation, thus causing the inflammatory response. According to this conclusion, the interaction between RANK and RANK-L is attributed to plaque destabilization, and it can be speculated that as a decoy receptor for RANK-L, OPG behaves as an antiinflammatory mediator (105). There are various studies that proclaim the angiogenetic and favorable effects of the interaction between RANK and RANK-L on endothelial cell survival (106108). Seccihiero et al. (109) demonstrated that adding RANK-L into cell cultures, regardless of OPG presence, showed protective effects on endothelial cells by activating intracellular pathways, which results in nitric oxide synthesis. In another study, increased OPG levels were found in the presence of TNF- $\alpha$, which can induce leukocyte adhesion molecule expression from endothelial cells and cause progression of atherogenesis (54).

OPG is a decoy receptor for TRAIL, which is attributed to TRAIL-associated apoptosis. TRAIL levels were found to have a negative correlation with CRP (110). Some researchers have concluded that by inhibiting TRAIL interaction with its receptor, OPG inhibits apoptosis and thereby intrudes the cellular barrier between the vessel lumen and plaque. In contrast, some researchers claim that OPG could increase leukocyte adhesion to endothelial cells both in vitro and in vivo with regard to the OPG's heparin-binding region (54). Based on these data, it can be concluded that OPG behaves as a proinflammatory mediator for endothelial cells (54). Another explanation that indicates the proinflammatory behavior of OPG is by inhibiting TRAIL. Administration of TRAIL was shown to exhibit an antiatherosclerotic activity in apolipoprotein E-null diabetic mice (109). Therefore, as a decoy receptor for TRAIL, OPG might serve in favor of atherogenesis.

The conflicting results reported by different studies may be attributed to the different ELISA kits used for measuring OPG levels. OPG measurements can be done in both plasma and serum; therefore, caution is needed when comparing OPG levels from different studies due to the differences among sample types (111). OPG gene polymorphisms (112) may be another explanation for the divergent results in different studies.

No consensus is yet available on the function of OPG, but all these studies have concluded that OPG is a promising biomarker for $\mathrm{CAD}$, regardless of whether it plays a protective role against atherosclerosis or causes atherosclerosis with its proatherogenic features. Further study is needed to define its role in pathogenesis and in the process of CVD. 
Conflict of Interest: No conflict of interest was declared by the authors.

Financial Disclosure: No financial disclosure was declared by the authors.

\section{REFERENCES}

1. Lopez ADM, CD, Ezzati M, Jamison DT, Murray CJ. Global Burden of Disease and Risk Factors: Disease Control Priorities Project. New York, NY: World Bank and Oxford University Press; 2006.

2. Yeboah J, Erbel R, Delaney JC, Nance R, Guo M, Bertoni AG, et al. Development of a new diabetes risk prediction tool for incident coronary heart disease events: the MultiEthnic Study of Atherosclerosis and the Heinz Nixdorf Recall Study. Atherosclerosis 2014;236:411-7.

3. Arroyo-Espliguero R, Avanzas P, Cosín-Sales J, Aldama G, Pizzi C, Kaski JC. C-reactive protein elevation and disease activity in patients with coronary artery disease. Eur Heart J 2004;25:401-8.

4. Manzi S, Meilahn EN, Rairie JE, Conte CG, Medsger TA Jr, Jansen-McWilliams $\mathrm{L}$, et al Age-specific incidence rates of myocardial infarction and angina in women with systemic lupus erythematosus: comparison with the Framingham Study. Am J Epidemiol 1997;145:408-15.

5. Chung CP, Oeser A, Raggi P, Gebretsadik T, Shintani AK, Sokka T, et al. Increased coronary-artery atherosclerosis in rheumatoid arthritis: relationship to disease duration and cardiovascular risk factors. Arthritis Rheum 2005;52:3045-53.

6. Simonet WS, Lacey DL, Dunstan CR, Kelley M, Chang MS, Lüthy R, et al. Osteoprotegerin novel secreted protein involved in the regulation of bone density. Cell 1997;89:309-19.

7. Bucay N, Sarosi I, Dunstan CR, Morony S, Tarpley J, Capparelli C, et al. Osteoprotegerin-deficient mice develop early onset osteoporosis and arterial calcification. Genes Dev 1998;12:1260-8.

8. Schoppet M, Preissner KT, Hofbauer LC. RANK ligand and osteoprotegerin. Paracrine regulators of bone metabolism and vascular function. Arterioscler Thromb Vasc Biol 2002;22:549-53

9. Hofbauer LC, Shui C, Riggs BL, Dunstan CR, Spelsberg TC, O'Brein T, et al. Effects of immunosuppressants on receptor activator of NF-kappaB ligand and osteoprotegerin production by human osteoblastic and coronary artery smooth muscle cells. Biochem Biophys Res Commun 2001;280:334-9.

10. Malyankar UM, Scantena M, Suchland KL, Yun TJ, Clark EA, Giachelli CM. Osteoprotegerin is an alpha vbeta 3-induced, NF-kappa B-dependent survival facto for endothelial cells. J Biol Chem 2000;275:20959-62.

11. Lieb W, Gona P, Larson MG, Massaro JM, Lipinska I, Keaney JF Jr. Biomarkers of the osteoprotegerin pathway: clinical correlates, subclinical disease, incident cardiovascular disease, and mortality. Arterioscler Thromb Vasc Biol 2010;30:184954.

12. Jono S, Ikari Y, Shioi A, Mori K, Miki T, Haran K, et al. Serum osteoprotegerin levels are associated with presence and severity of coronary artery disease. Circulation 2002;106:1192-4.

13. Uyama O, Yoshimoto Y, Yamamoto Y, Kawai A. Bone changes and carotid atherosclerosis in postmenopausal women. Stroke 1997;28:1730-2.

14. Browner WS, Lul LY, Cumming SR. Association of serum osteoprotegerin levels with diabetes, stroke, bone density, fractures, and mortality in elderly women. J Clinic Endocrinol Metab 2001;86:631-7

15. Ueland T, Yndestad A, Oie E, Florhormen G,Halvorsen B, Frøland SS, et al. Dysregulated osteoprotegerin/RANK ligand/RANK axis in clinical and experimental heart failure. Circulation 2005;111:2461-8.

16. Xi L, Cao H, Zhu J, Roe OD, Li M, Wu Y, et al. OPG/RANK/RANKL axis in stabilization of spontaneously restored sinus rhythm in permanent atrial fibrillation patients after mitral valve surgery. Cardiology 2013;124:18-24.

17. Hofbauer LC, Heufelder AE. Role of receptor activator of nuclear factor-kappaB ligand and osteoprotegerin in bone cell biology. J Mol Med (Berl) 2001;79:24353.

18. Yamaguchi K, Kinosaki M, Goto M, Kobayashi F, Tsuda E, Morinaga T, et al Characterization of structural domains of human osteoclastogenesis inhibitory factor J Biol Chem 1998;273:5117-23.

19. Yun TJ, Chaudhary PM, Shu GL, Frazer JK, Ewings MK, Schwartz SM, et al. OPG/ FDCR-1, a TNF receptor family member, is expressed in lymphoid cells and is upregulated by ligating CD40. J Immunol 1998;161:6113-21.
20. Lacey DL, Timms E, Tan HL, Kelley MJ, Dunstan CR, Burgess T, et al Osteoprotegerin ligand is a cytokine that regulates osteoclast differentiation and activation. Cell 1998;93:165-76.

21. Zhang J, Fu M, Myles D, Zhu X, Du J, Cao X, et al. PDGF induces osteoprotegerin expression in vascular smooth muscle cells by multiple signal pathways. FEBS Lett 2002;521:180-4

22. Fu M, Zhang J, Lin Yq Yq, Zhu X, Wilson TM, Chen YE. Activation of peroxisome proliferator-activated receptor gamma inhibits osteoprotegerin gene expression in human aortic smooth muscle cells. Biochem Biophys Res Commun 2002;294:597601.

23. Ishida A, Fujita N, Kitazava R, Tsuruo T. Transforming growth factor-beta induces expression of receptor activator of NF-kappa B ligand in vascular endothelial cells derived from bone. J Biol Chem 2002;277:26217-24.

24. Ashley DT, O'Sullivan EP, Davenport C, Devlin N, Crowley RK, McCaffrey N, et al Similar to adiponectin, serum levels of osteoprotegerin are associated with obesity in healthy subjects. Metabolism 2011;60:994-1000.

25. Kazama JJ, Kato H, Sato T, Shigematsu T, Fukagava M, Iwasaki Y, et al. Circulating osteoprotegerin is not removed through haemodialysis membrane. Nephrol Dial Transplant 2002;17:1860-1.

26. Schoppet M, Sattler AM, Schaefer JR, Herzum M, Maisch B, Hofbauer LC. Increased osteoprotegerin serum levels in men with coronary artery disease. J Clin Endocrinol Metab 2003;88:1024-8

27. Szulc P, Hofbauer LC, Heufelder AE, Roth S, Delmas PD. Osteoprotegerin serum levels in men: correlation with age, estrogen, and testosterone status. J Clin Endocrinol Metab 2001;86:3162-5.

28. Knudsen ST, Foss CH, Poulsen PL, Anderson NH, Morgensen CE, Rasmussen LM. Increased plasma concentrations of osteoprotegerin in type 2 diabetic patients with microvascular complications. Eur J Endocrinol 2003;149:39-42.

29. Kazama JJ, Shigematsu T, Yano K, Tsuda E, Mitura M, Iwasaki W, et al. Increased circulating levels of osteoclastogenesis-inhibitory factor (osteoprotegerin) in patients with chronic renal failure. Am J Kidney Dis 2002;39:525-32

30. Khosla S, Arrighi HM, Melton LJ, Atkinson EJ, O'Fallon WM, Dunstan C, et al. Correlates of osteoprotegerin levels in women and men. Osteoporos Int 2002;13:3949.

31. Arrighi HM, Hsieh A, Wong H, et al. Osteoprotegerin serum levels in healthy volunteers. J Bone Miner Res 1998;14:518-27.

32. Victor RG, Haley RW, Willett DL, Peshock RM, Vaeth PC, Leonard D, et al. The Dallas Heart Study: A population-based probability sample for the multidisciplinary study of ethnic differences in cardiovascular health. Am J Cardiol 2004;93:1473-80.

33. Persy V, D'Haese P. Vascular calcification and bone disease: the calcification paradox Trends Mol Med 2009;15:405-16.

34. Arrighi H, Khosla S, Melton LJ, Riggs B, Bekker P, Dunstan CR. The relationship between circulating osteoprotegerin and estrogen in postmenopausal women. J Bone Miner Res 2000;15:344.

35. Hofbauer LC, Khosla S, Dunstan CR, Lacey DL, Spelsberg TC, Riggs BL. Estrogen stimulates gene expression and protein production of osteoprotegerin in human osteoblastic cells. Endocrinology 1999;140:4367-70.

36. Bekker PJ, Holloway D, Nakanishi A, Arrighi HM, leese PT, Dunstan CR. OPG the effect of a single dose of osteoprotegerin in postmenopausal women. Miner Res 2001;16:348-60.

37. Price PA, June HH, Buckley JR, Williamson MK. Osteoprotegerin inhibits artery calcification Induced by warfarin and by Vitamin D. Arterioscler Thromb Vasc Biol 2001;21:1610-6.

38. Greenland P, LaBree L, Azen SP, Doherty TM, Detrano RC. Coronary artery calcium score combined with Framingham score for risk prediction in asymptomatic individuals. JAMA 2004;291:210-5.

39. Chapman I. Anatomic and clinical significance of calcification of the aortic knob visualized radiographically. Am J Cardiol 1960;6:281-6.

40. Schoppet M, Al-Fakhri N, Franke FE, Katz N, Barth PJ, Maisch B, et al. Localization of osteoprotegerin, tumor necrosis factor-related apoptosis-inducing ligand, and receptor activator of nuclear factor KappaB ligand in mönckeberg's sclerosis and atherosclerosis. J Clin Endocrinol Metab 2004;89:4104-12.

41. Dhore CR, Cleutjens JP, Lutgens E, Cleutjens KB, Geusens PP, Kitslaar PJ, et al Differential expression of bone matrix regulatory proteins in human atherosclerotic plaques. Arterioscler Thromb Vasc Biol 2001;21:1998-2003. 
42. Anand DV, Lahiri A, Lim E, Hopkins D, Corder R. The relationship between plasma osteoprotegerin levels and coronary artery calcification in uncomplicated type 2 diabetic subjects. J Am Coll Cardiol 2006;47:1850-7.

43. Ghaffari S, Yaghoubi A, Baghernejad R, Sepehrvand N. Sokhanvar S, Haghjou AG. The value of serum osteoprotegerin levels in patients with angına like chest pain undergoing diagnostic coronary angiography. Cardiol J 2013;20:261-7.

44. Kiechl S, Schett G, Wenning G, Redlich K, Oberhollenzer M, Mayr A, et al. Osteoprotegerin is a risk factor for progressive atherosclerosis and cardiovascular disease. Circulation 2004;109;2175-80.

45. Poornima IG, Mackey RH, Buhari AM, Cauley JA, Matthews KA, Kuller LH. Relationship between circulating serum osteoprotegerin and total receptor activator of nuclear $\kappa-\beta$ ligand levels, triglycerides, and coronary calcification in postmenopausal women. Menopause 2014;21:702-10.

46. Altun A, Ugur Altun B, Tatli E. Decreased serum osteoprotegerin levels in patients with cardiac syndrome X. J Endocrinol Invest 2004;27:839-43.

47. Nascimento MM, Hayashi SY, Riella MC, Lindholm B. Elevated levels of plasma osteoprotegerin are associated with all-cause mortality risk and atherosclerosis in patients with stage 3 to 5 chronic kidney disease. Braz J Med Biol Res 2014;47:9951002.

48. Morena M, Dupuy AM, Jaussent I, Vernhet H, Gahide G, Klouche K, et al. A cutoff value of plasma osteoprotegerin level may predict the presence of coronary artery calcifications in chronic kidney disease patients. Nephrol Dial Transplant 2009;24:3389-97.

49. Morena M, Jaussent I, Dupuy AM, Bargnoux AS, Kuster N, Chenine L, et al. Osteoprotegerin and sclerostin in chronic kidney disease prior to dialysis: potential partners in vascular calcifications. Nephrol Dial Transplant 2015;30:1345-56.

50. Pedersen S, Mogelvang R, Bjerre M, Frystyk J, Flyvbjerg A, Galatius S, et al. Osteoprotegerin predicts long-term outcome in patients with ST-segment elevation myocardial infarction treated with primary percutaneous coronary intervention. Cardiology 2012;123:31-8.

51. Jansson AM, Hartford M, Omland T, Karlsson T, Karlsson T, Lindmarker P, Herlitz J. Multimarker risk assessment including osteoprotegerin and CXCL 16 in acute coronary syndromes. Arterioscler Thromb Vasc Biol 2012;32;3041-9.

52. Luo ZR, Zheng WX, Huang MF, Chen H, Wang ZQ. A study of relationship between dialectical classification according to traditional Chinese medicine of acute coronary syndrome with serum osteoprotegerin and its ligands. Zhonghua Wei Zhong Bing Ji Jiu Yi Xue 2013;25:673-6.

53. Aksu F, Ozçelik F, Kunduracilar H, Barutçu A, Yel M, Umit EG, et al. The relation between the levels of osteoprotegerin and the degree of coronary artery disease in patients with acute coronary syndrome and stable angina pectoris. Kardiol Pol 2014;72:34-41.

54. Zauli G, Corrallini F, Bossi F, Fischetti F, Durigutto P, Celeghini C, et al. Osteoprotegerin increases leukocyte adhesion to endothelial cells both in vitro and in vivo. Blood 2007;15;110:536-43.

55. Ziegler S, Kudlacek S, Luger A, Minar E. Osteoprotegerin plasma concentrations correlate with severity of peripheral artery disease. Atherosclerosis 2005;182:175-80.

56. Lee CJ, Wang JH, Chen ML, Yang CF, Chen YC, Hsu BG. Serum osteoprotegerin is associated with arterial stiffness assessed according to the cardio-ankle vascular index in hypertensive patients. J Atheroscler Thromb 2015;22:304-12.

57. Esteghamati A, Aflatoonian M, Red MV, Mazaheri T, Mousavizadeh M, Nakhjavani $\mathrm{M}$, et al. Association of osteoprotegerin with peripheral artery disease in patients with type 2 diabetes. Arch Cardiovasc Dis 2015;108:412-9.

58. Oğuz D, Ünal HÜ, Eroğlu H, Gülmez O, Çevik H, Altun A. Aortic flow propagation velocity, epicardial fat thickness, and osteoprotegerin level to predict subclinical atherosclerosis in patients with nonalcoholic fatty liver disease. Anatol J Cardiol 2016;16:974-9.

59. Akinci B, Demir T, Celtik A, Baris M, Yener S, Ozcan MA, et al. Serum osteoprotegerin is associated with carotid intima media thickness in women with previous gestational diabetes. Diabetes Res Clin Pract 2008;82:172-8.

60. Mogelvang R, Haahr-Pedersen S, Bjerre M, Frystyk J, Iversen A, Galatius S, et al. Osteoprotegerin improves risk detection by traditional cardiovascular risk factors and hsCRP. Heart 2013;99:106-10.

61. Bots ML, Hoes AW, Koudstaal PJ, Hofman A, Grobbee DE. Common carotid intimamedia thickness and risk of stroke and myocardial infarction. The Rotterdam Study. Circulation 1997;96:1432-7.
62. Kuller LH, Shemanski L, Psaty BM, Borhani NO, Gardin J, Haan MN, et al. Subclinical disease as an independent risk factor for cardiovascular disease. Circulation 1995;92:720-6.

63. Nybo M, Johnsen SP, Dethlefsen C, Overvad K, Tionneland A, Jorgensen JO, et al. Lack of observed association between high plasma osteoprotegerin concentrations and ischemic stroke risk in a healthy population. Clin Chem 2008;54:1969-74.

64. Üstündağ M, Orak M, Güloğlu C, Tamam Y, Sayhan MB, Kale E. The role of serum osteoprotegerin and S-100 protein levels in patients with acute ischaemic stroke: determination of stroke subtype, severity and mortality. J Int Med Res 2011;39:7809 .

65. Guldiken B, Guldiken S, Turgut B, Turgut N, Demir M, Celik Y, et al. Serum osteoprotegerin levels in patients with acute atherothrombotic stroke and lacunar infarct. Thromb Res 2007;120:511-6.

66. Omland T, Drazner MH, Ueland T, Abedin M, Murphy SA, Aukrust P, et al. Plasma osteoprotegerin levels in the general population relation to indices of left ventricular structure and function. Hypertension 2007;49:1392-8.

67. Omland T, Ueland T, Jansson AM, Persson A, Karlsson T, Smith C, et al. Circulating osteoprotegerin levels and long-term prognosis in patients with acute coronary syndromes. J Am Coll Cardiol 2008;51:627-33.

68. Zannettino AC, Holding CA, Diamond P, Atkins GJ, Kostakis P, Farrugia A, et al. Osteoprotegerin (OPG) is localized to the Weibel Palade bodies of human vascular endothelial cells and is physically associated with von Willebrand factor. J Cell Physiol 2005;204:714-23.

69. Lis GJ, Czubek U, Jasinska M, Jasek E, Loboda A, Dulak J, et al. Elevated serum osteoprotegerin is associated with decreased osteoclastic differentiation in stenotic aortic valves. J Physiol Pharmacol 2014;65:377-82.

70. Mohler ER, Gannon F, Reynolds C, Zimmerman R, Keane MG, Kaplan FS. Bone formation and inflammation in cardiac valves. Circulation 2001;103:1522-8.

71. Weiss RM, Lund DD, Chu Y, Brooks RM, Zimmerman KA, El Accaoui RE, et al. Osteoprotegerin inhibits aortic valve calcification and preserves valve function in hypercholesterolemic mice. PLoS One 2013;8:e65201.

72. Asaba Y, Ito M, Fumoto T, Watanabe K, Fukuhara R, Takeshita S, et al. Activation of renin-angiotensin system induces osteoporosis independently of hypertension. J Bone Miner Res 2009;24:241-50.

73. Shimizu H, Nakagami H, Osako MK, Hanayama R, Kunugiza Y, Kizawa T, et al. Angiotensin II accelerates osteoporosis by activating osteoclasts. FASEB J 2008;22:2465-75.

74. Moran CS, McCann M, Karan M, Norman P, Ketheesan N, Golledge J. Association of osteoprotegerin with human abdominal aortic aneurysm progression. Circulation 2005;111:3119-25.

75. Wang JH, Lee CJ, Chen ML, Yang CF, Chen YC, Hsu BG. Association of serum osteoprotegerin levels with carotid-femoral pulse wave velocity in hypertensive patients. J Clin Hypertens (Greenwich) 2014;16:301-8.

76. Tomiyama H, Yamashina A. Non-invasive vascular function tests: Their pathophysiological background and clinical application. Circ J 2010;74:24-33.

77. Akyuz A, Oran M, Alpsoy S, Mutlu LC, Degirmenci H, Kucukyalın V, et al Association between drug-resistant hypertension and increased osteoprotegerin levels in hypertensive male patients with non-obstructive sleep apnea. Acta Medica Mediterr 2014;30:1381-6.

78. Oh ES, Rhee EJ, Oh KW, Lee WY, Baek KH, Yoon KH, et al. Circulating osteoprotegerin levels are associated with age, waist-to-hip ratio, serum-total cholesterol, and low-density lipoprotein cholesterol levels in healthy Korean women. Metabolism 2005;54:49-54.

79. Olesen P, Ledet T, Rasmussen LM. Arterial osteoprotegerin: increased amounts in diabetes and modifiable synthesis from vascular smooth muscle cells by insulin and TNF-alpha. Diabetologia 2005;48:561-8.

80. Galluzzi F, Stagi S, Salti R, Toni S, Piscitelli E, Simonini G, et al. Osteoprotegerin serum levels in children with type 1 diabetes: a potential modulating role in bone status. Eur J Endocrinol 2005;153:879-85.

81. Avignon A, Sultan A, Piot C, Elaerts S, Cristol JP, Dupuy AM. Osteoprotegerin is associated with silent coronary artery disease in high risk but asymptomatic type 2 diabetic patients. Diabetes Care 2005;28:2176-80.

82. Avignon A, Sultan A, Piot C, Mariano-Goulart D, Thuan Dit Dieudonne JF, Cristol JP, et al. Osteoprotegerin: a novel independent marker for silent myocardial ischemia in asymptomatic diabetic patients. Diabetes Care 2007;30:2934-9. 
83. Grauslund J, Rasmussen LM, Green A, Sjolie A. Does osteoprotegerin relate to microvascular complications in long-term type 1 diabetes? Scand J Clin Lab Invest 2010;70:188-93.

84. Seccihero P, Corrallini F, Pandolfi A, Consoli A, Candido R, Fabris B, et al. An increased osteoprotegerin serum release characterizes the early onset of diabetes mellitus and may contribute to cell dysfunction. Am J Pathol 2006;169:2236-44.

85. Collin-Osdoby P, Rothe L, Anderson F, Nelson M, Maloney W, Osdoby P. Receptor activator of NF-kappa B and osteoprotegerin expression by human microvascular endothelial cells, regulation by inflammatory cytokines, and role in human osteoclastogenesis. J Biol Chem 2001;276;20659-72.

86. Gannage-Yared MH, Fares F, Semaan M, Khalife S, Jambart S. Circulation osteoprotegerin is correlated with lipid profile, insulin sensitivity adiponectin and sex steroids in an ageing male population. Clin Endocrinol (Oxf) 2006;64:652-8.

87. Ugur Altun B, Altun A, Gerenli M, Tugrul A. The relationship between insulin resistance assessed by HOMA-IR and serum osteoprotegerin levels in obesity. Diabetes Res Clin Pract 2005;68:217-22.

88. Ugur Altun B, Altun A. Circulating Leptin and Osteoprotegerin Levels Affect Insulin Resistance in Healthy Premenopausal Obese Women. Arch Med Res 2007;38:891-6.

89. Knudsen ST, Jeppesen P, Poulsen PL, Andersen NH, Bek T, Schmitz O, et al. Plasma concentrations of osteoprotegerin during normo- and hyperglycaemic clamping. Scand J Clin Lab Invest 2007;67:135-42.

90. Jorgensen GM, Vind B, Nybo M, Rasmussen LM, Hojlund K. Acute hyperinsulinemia decreases plasma osteoprotegerin with diminished effect in type 2 diabetes and obesity. Eur J Endocrinol 2009;161:95-101.

91. Kahn R, Buse J, Ferrannini E, Stern M; American Diabetes Association and European Association for the Study of Diabetes. The Metabolic syndrome: Time for a critical appraisal: Joint Statement from the American Diabetes Association and the European Association for the Study of Diabetes. Diabetes Care 2005;28:2289-304.

92. Carr DB, Utzschneider KM, Hull RL,Kodama K, Retzlaff BM, Brunzell JD, et al. Intra- abdominal fat is a major determinant of the National Cholesterol Education Program Adult Treatment Panel III criteria for the metabolic syndrome. Diabetes 2004;53:2087-94.

93. Guilherme A, Virbasius JV, Puri V, Czech MP. Adipocyte dysfunctions linking obesity to insulin resistance and type 2 diabetes. Nat Rev Mol Cell Biol 2008;9:367-77.

94. Weisberg SP, McCann D, Desai M, Rosenbaum M, Leibel RL, Ferrante AW Jr. Obesity is associated with macrophage accumulation in adipose tissue. J Clin Invest 2003; 112:1796-808.

95. Bernardi S, Fabris B, Thomas M, Toffoli B, Tikellis C, Candido R, et al. Osteoprotegerin increases in metabolic syndrome and promotes adipose tissue proinflammatory changes. Mol Cell Endocrinol 2014;394:13-20.

96. Nellemann B, Gormsen LC, Dollerup J, Schmitz O, Mogensen CE, Rasmussen LM, et al. Simvastatin reduces plasma osteoprotegerin in type 2 diabetic patients with microalbuminuria. Diabetes Care 2007;30:3122-4.
97. Nezami N, Safa J, Eftekhar-Sadat AT, Salari B, Ghorashi S, Sakhaee K, et al. Lovastatin raises serum osteoprotegerin level in people with type 2 diabetic nephropathy. Clin Biochem 2010;43:1294-9.

98. Mori K, Jono S, Emoto M, Kawagishi T, Yasumoto H, Konishi T, et al. Effects of pravastatin on serum osteoprotegerin levels in patients with hypercholesterolemia and type 2 diabetes. Angiology 2010;61:86-91.

99. Hosbond SE, Poulsen TS, Diederichsen AC, Nybo M, Rasmussen LM, Mickley H. Osteoprotegerin as a marker of atherosclerosis: A systemic update. Scand Cardiovasc J 2012;46:203-11

100. Abedin M, Tintut Y, Demer LL. Vascular calcification: mechanisms and clinical ramifications. Arterioscler Thromb Vasc Biol 2004;24:1161-70.

101. Tintut Y, Alfonso Z, Saini T, Radcliff K, Watson K, Boström K, et al. Multilineage potential of cells from the artery wall. Circulation 2003;108:2505-10.

102. Proudfoot D, Shanahan CM. Biology of calcification in vascular cells: intima versus media. Herz 2001;26:245-51.

103. Lakatta EG, Mitchell JH, Pomerance A, Rowe GG. Human aging: changes in structure and function. J Am Coll Cardiol 1987;(2 Suppl A)10:42-7.

104. Safar ME, Edward D. Frohlich. Large Arteries and Cardiovascular Risk. Atherosclerosis, Press; 2007:44:117-24.

105. Shaker OG, El-Shehaby A, Nabih M. Possible role of osteoprotegerin and tumor necrosis factor-related apoptosis-inducing ligand as markers of plaque instability in coronary artery disease. Angiology 2010;61:756-62.

106. Min JK, Kim YM, Kim YM, Kim EC, Gho YS, Kang IJ, et al. Vascular endothelial growth factor up-regulates expression of receptor activator of NF-kappa B (RANK) in endothelial cells. Concomitant increase of angiogenic responses to RANK ligand. J Biol Chem 2003;278:39548-57.

107. Kim YM, Kim YM, Lee YM, Kim HS, Kim JD, Choi Y, et al. TNF-related activationinduced cytokine (TRANCE) induces angiogenesis through the activation of Src and phospholipase C (PLC) in human endothelial cells. J Biol Chem 2002;277:6799-805.

108. Kim HH, Shin HS, Kwak HJ, Ahn KY, Kim JH, Lee MS, et al. RANKL regulates endothelial cell survival through the phosphatidylinositol 3-kinase/Akt signal transduction pathway. FASEB J 2003;17:2163-5.

109. Seccihiero P, Candido R, Corallini F, Zacchigna S, Toffoli B, Rimondi E, et al. Systemic tumor necrosis factor-related apoptosis-inducing ligand delivery shows antiatherosclerotic activity in apolipoprotein E-null diabetic mice. Circulation 2006;114:1522-30.

110. Michowitz Y, Goldstem E, Roth A, Afek A, Abashidze, Ben Gal Y, et al. The involvement of tumor necrosis factor related apoptosis-inducing ligand (TRAIL) in atherosclerosis. J Am Coll Cardiol 2005;45:1018-24.

111. Perez de Ciriza C, Lawrie A, Varo N. Influence of preanalytical and analytical factors on osteoprotegerin measurments. Clin Biochem 2014:47:1279-85.

112. Mankoc-Ramus S, Kumse T, Globocnik Petrovic M, Petrovic D, Cilensek I. SNP rs 2073618 of the osteoprotegerin gene is associated with diabetic retinopathy in Slovenian patients with type 2 diabetes. Bio Med Res Int 2013;2013:364073. 